\title{
Precedent-based Legal Reasoning and Knowledge Acquisition in Contract Law: A Process Model
}

\author{
Seth R. Goldman \\ Michael G. Dyer \\ Margot Flowers \\ Artificial Intelligence Laboratory \\ 3531 Boelter Hall \\ University of California, Los Angeles \\ Los Angeles, CA 90024
}

\begin{abstract}
In the law, decisions in previous cases play a significant role in the presentation, understanding, and outcome of new cases. This is particularly true in the area of contract law where few statutes (explicit legal rules) exist. When presented with a new case, a lawyer must be able to identify important issues and make some predictions about how the case might be decided. The lawyer will often recall past cases which bear similarities to the current case and reason analogically to make these predictions. In order to perform these tasks, a lawyer must be able to remember past cases, organize them in memory so that cases that are conceptually similar are stored together (a lawyer normally won't be reminded of an irrelevant case), and make analogies between cases. Thus the organization and representation of knowledge in memory is crucial in building a model of a lawyer's cognitive processes. This paper describes a process model, implemented in a computer program called STARE, which addresses these issues in the context of first-year law students learning contract law.
\end{abstract}

\section{Introduction}

In the law, precedents play a significant role in the interpretation, presentation, and resolution of new cases. In some areas of law, such as tax law, there is a large body of rules (statutes and regulations) which can be used to decide the majority of cases. However, in contract law, there are few statutes, so decisions must be based at least partly on precedent cases. When presented with a new case, a lawyer must be able to identify the important issues and make some predictions about how the case may be resolved.

Our research focuses on building a computational model of the cognitive processes involved in remembering, recalling, and applying past experiences to new situations. Contract law provides a rich domain for studying these processes because it involves the use of precedent cases to decide new cases. To study these processes, it makes sense to begin by examining how contract law is taught. The primary purpose of law school is to teach the students to think like lawyers. Thinking like a lawyer involves learning how to apply precedents and legal principles to novel situations.

We have built a process model which describes aspects of these types of behavior and implemented an initial prototype in a computer program called STARE ${ }^{1}$ (Goldman, 1986; Goldman, Dyer, \& Flowers, 1985a, 1985b). The following examples illustrate the processes STARE models, and highlight the important research issues involved in this kind of cognitive

1 STARE comes from the latin, stare decisis, which means 'let the decision stand' and is used to refer to the principle of using precedent cases to decide new cases.

Permission to copy without fec all or part of this material is granted provided that copies are not made or distributed for direct commercial advantage, ACM copyright notice and the title of the publication and its date appear, and notice is given that copying is by permission of the ACM. To copy notice is given that copying is by permission of the ACM. To

(c) ACM 0-89791-230-6/87/0500/0210 $\$ 0.75$ modeling.

\subsection{What STARE Is Up Against}

STARE processes conceptual representations of simple paragraphs which describe potential contractual situations between two parties. The cases are drawn from (Eisenberg, 1982). STARE must determine whether or not a contract actually exists under the principles of contract law. STARE decides based upon its legal knowledge and situations it has stored in episodic memory. A typical case is:

\section{Merchant y. Vacationer}

O'Hara, a police officer on vacation in Florida, promises Alfred, a store owner, that he will keep an eye on Alfred's store during Alfred's lunch hour if Alfred will pay him \$10. Alfred agrees to pay O'Hara \$10.

Is there a contract in this situation? Answering this question requires (1) knowledge about social roles such as policemen, store owners, and public servants, (2) what effect being "on vacation" has for O'Hara, (3) what it means to "promise" to do something, (4) what it means to "keep an eye" on something. and (5) what it means to agree to something. In addition, there are many inferences we can make. One such inference is that O'Hara wants to earn some money while on vacation. Now consider the following:

\section{Merchant y. Conner}

Fred, a police officer, promises Barney, a merchant who owns a store on Fred's beat, that he will keep an eye on Barney's store if Barney pays him $\$ 50$ per month. Barney agrees to pay Fred $\$ 50$ per month.

Merchant v. Copper shares many surface features with Merchant $\checkmark$. Vacationer. Both cases involve negotiations between a policeman and a merchant who is concerned with obtaining protection for the store from the policeman. However, most people we asked concluded that there is no contract (or at least that something is very wrong) based upon the conflict arising from Fred's actions. As a police officer, he is obligated to watch over the stores on his beat, yet he is trying to earn additional money by watching Barney's store which he is already supposed to do. In addition to the knowledge that we need to understand the first situation, Merchant v. Copper requires us to know about the relationship of policemen to the public in general and that a person should not be paid twice for the same task. Now consider:

\section{Witness y. Citizen}

John promises to tell the truth as a witness in court if Mary will promise to pay John $\$ 100$. Mary promises to pay John $\$ 100$. 
This situation does not resemble either of the previous episodes on the surface, however, there are similarities to Merchant $v$. Copper at a-deeper level. At this deeper level, we have an attempt by John to be paid for something John is already supposed to do. Understanding the situation means constructing a deep representation for the underlying common sense and legal concepts and relating the situation to previous experience.

\subsection{STARE Overview}

STARE takes as input a conceptual representation of a situation (currently hand-coded) and produces as output a decision as to whether there is or is not a contract in the given situation. This decision is supported by STARE's common sense and legal knowledge as well as any past experiences which were involved in the decision. In this section we outline the general processes STARE uses to understand a situation and produce a decision and describe the issues which we will address later in this paper.

The following figures depict STARE's input and output behavior while processing Witness $v$. Citizen.

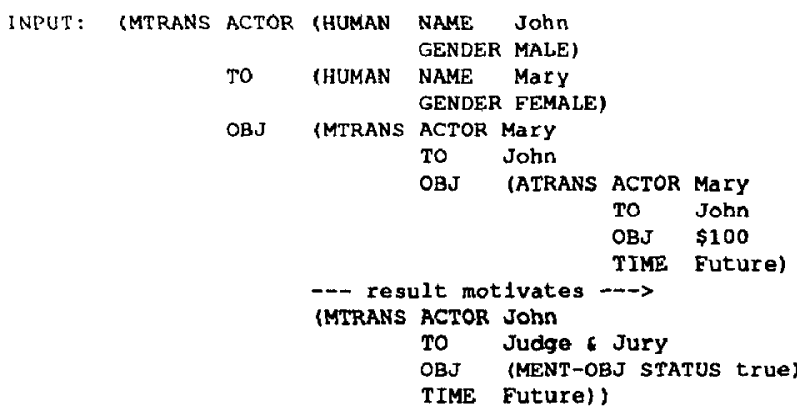

The diagram above shows the representation of John's offer which is based upon Conceptual Dependency (CD) Theory (Schank, 1977). MTRANS stands for some kind of communication (e.g., promise, tell) and ATRANS stands for a physical transfer of an object (e.g., give, take). The diagram represents John telling Mary that Mary promising to give John $\$ 100$ later will enable John to tell the truth to the judge and jury. The representation for judge is a human with the occupation of being a judge. The jury is represented as a group of humans. A simplified version of the output STARE produces while processing this conceptual fragment follows:

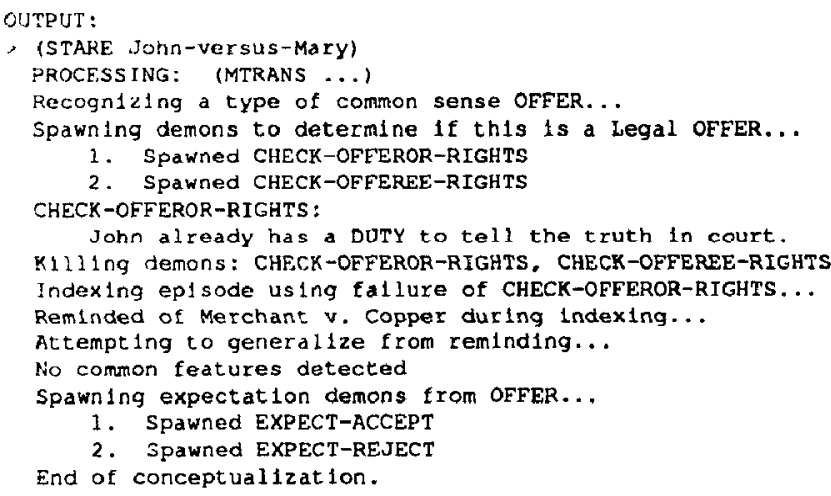

The first thing that STARE does is try to interpret the MTRANS in terms of a higher level knowledge structure. STARE finds one corresponding to a common sense offer and instantiates it. This raises the following questions:

- What is the representation for concepts like PROMISE and OFFER?

- How are these concepts stored in memory?
Instantiating a knowledge structure involves making certain inferences. Attached to the common sense concept OFFER are rules which determine if this instance is an instance of the legal concept OFFER.

- How does a legal OFFER differ from a common sense OFFER?

- What are these inference rules and how are they stored in memory?

STARE spawns two demons (Dyer, 1983) to verify that the MTRANS is a legal offer. One of these demons, CHECKOFFEROR-RIGHTS, fails because it discovers that John does not have the right to make such an offer.

- How are legal relations represented and recognized?

Once the demon fails STARE kills off both demons and uses the failure to index this part of the entire episode in memory. During this process STARE is reminded of Merchant v. Copper because of a similar failure. STARE tries to make a generalization based upon the two situations but fails to find any common features.

- How is memory organized and how are generalizations made?

Finally, STARE spawns some expectation demons associated with common sense OFFER which will guide the understanding of the next input conceptualization. The representation for Mary's response is:

$\begin{array}{llll}\text { INPUT: (MTRANS ACTOR } & \text { Mary } & \\ \text { TO } & \text { John } & \\ \text { OBJ } & \text { (ATRANS ACTOR Mary } & \text { TO } & \text { John } \\ & & \text { TIME } & \text { Fut ure } \\ & & \text { OBJ } & \text { \$100)) }\end{array}$

Mary's response is to tell John that she will give him $\$ 100$ at a future time. We have not dealt very much with the representation of time. In this case, future refers to a time after John has told the truth in court. STARE's output for this fragment is:

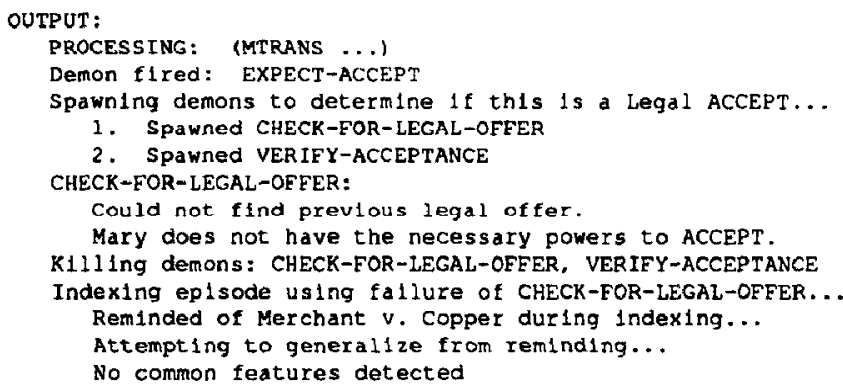

Although the first conceptual fragment was not a legal offer, it was a common sense offer and one of the possible responses is an acceptance. This is what triggers the EXPECT-ACCEPT demon.

\section{- What is the role of expectations during processing?}

The inferences for an acceptance include checking to see if the acceptance is legal (as opposed to just making sense). This results in a failure because there was no preceding legal offer. The failure results in this part of the episode to be indexed in memory together with Merchant $v$. Copper, triggering a reminding of this case.

STARE has now run out of input so it decides whether a contract exists and the reasons why. STARE's decision in Witness v. Citizen is: 
OUTPUT:

$$
\begin{aligned}
& \text { DECISION: There is no contract between John and Mary. } \\
& \text { REASONS: John's offer was not a legal offer because John } \\
& \text { already has a DUTY to tell the truth in court. } \\
& \text { Mary's acceptance was not legal because there } \\
& \text { was no preceding legal of fer. } \\
& \text { REMINDINGS: Merchant } v \text {. Copper }
\end{aligned}
$$

STARE was reminded of a previous case, Merchant $\boldsymbol{v}$. Copper, because there is a conflicting duty for the offeror in both cases. This reminding is used to confirm the decision that there is no contract.

\subsection{STARE Architecture}

Below is a block diagram for the entire STARE system. Currently only the Legal Understander and Episodic Memory components have been implemented and will be discussed in this paper; however, the diagram provides an overall perspective of our research goals.

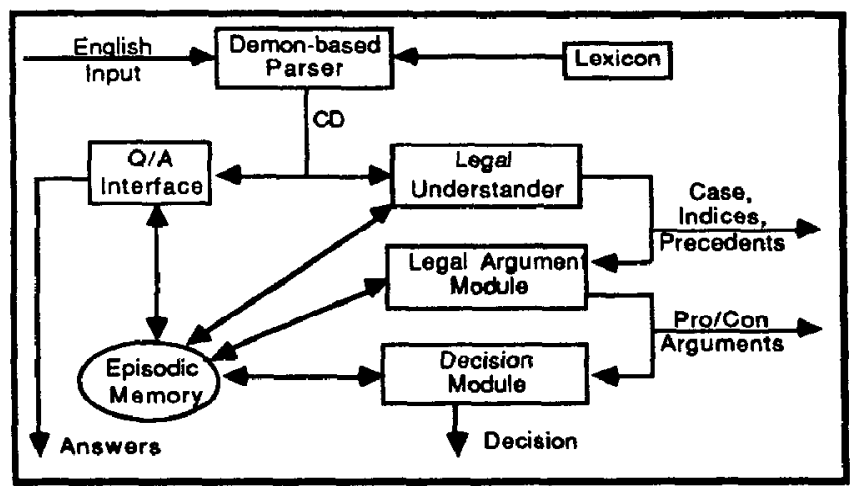

The input to the system will ultimately be English descriptions of situations such as those appearing earlier in this section. The English will be processed by a demon-based parser (Dyer, 1983) which produces conceptual fragments like those shown earlier. STARE operates in two different modes: analysis mode and question answering mode.

In analysis mode, the output from the parser is passed to the Legal Understander which uses Episodic Memory, legal knowledge, and common sense knowledge to produce a legal interpretation of the input. The output from the Legal Understander is an enhanced representation of the input and Episodic Memory indices to remindings which occurred during understanding. This output is sent to the Legal Argument module which contains knowledge about argumentation and strategies for making legal arguments. This module produces a set of reasoning chains which lead to different decisions. It is then up to a Decision module to evaluate these reasoning chains and select the best one.

In question answering mode, the output from the parser is passed to the Q/A module which accesses Episodic Memory to answer questions about the initial understanding of the situation, the arguments that were made, or the final decision.

Currently we have only implemented the Legal Understander and Episodic Memory modules. We started with these because they are crucial to the rest of the system. All of the components in the diagram rely upon past experience, world knowledge, and legal knowledge to perform their tasks. This information is contained in these two modules.

\subsection{Research Goals and Methodology}

There have been many different research projects over the past decade investigating the applications of artificial intelligence (A.I) to the legal domain, each with its own methodology. 2 One of the earliest projects took a frame-based approach, trying to match the input against pre-defined templates and then looking up the answer (Meldman, 1975). Others have taken an expert systems approach using large numbers of rules to encode legal knowledge (Peterson \& Waterman, 1985). There has also been work on developing a formal representation for legal rules and documents in an effort to eliminate ambiguity (deBessonet \& Cross, 1985; Allen \& Saxon, 1985). Finally, there are projects which try to address the problems involved in recognizing and representing legal issues and decisions (Gardner, 1984; McCarty \& Sridharan, 1981).

Our approach differs from those above in that we are primarily interested in the cognitive issues involved in understanding contractual situations and decisions. Contract law provides a rich domain for studying the cognitive processes relating to:

- the organization, storage, and retrieval of episodes in an episodic memory

- the acquisition and refinement of knowledge

- the interactions between different types of knowledge structures

- how remindings occur and affect processing

The example presented in $\$ 1.2$ showed how these different issues arise in the context of understanding a situation that potentially involves a contract. The rest of this paper is concerned with answering the questions raised in that section.

\section{Representing Legal Knowledge}

In order for STARE to understand contractual situations, it must be able to manipulate the concepts underlying the events it reads about. To do this, STARE incorporates different types of knowledge structures to represent different aspects of those events, including: conceptual dependency (Schank, 1972), goals (Wilensky, 1978), plans (Schank \& Abelson, 1977). events (Kolodner, 1984), role themes (Schank \& Abelson, 1977; Dyer, 1983), and social acts (Schank \& Carbonell, 1979). These knowledge structures enable us to represent the physical events and some of the intentions and motivations of the characters in a story. However, understanding a story about a possible contract also requires a representation for the legal relationships between the characters and a model of how those relationships are created and altered. Legal relationships are created and modified as a result of the actions of the characters in a particular situation.

\subsection{Legal ACTs For Contract Formation}

Consider the following situation:

\section{Sober y. Puritan 3}

Uncle Puritan promises Nephew Sober $\$ 5000$ if Nephew Sober will abstain from smoking and drinking until he turns 21 . Nephew Sober agrees.

We can represent the above situation in terms of $C D$ primitives MTRANS, ATRANS, and INGEST as shown below. However, this level of representation only captures the physical events that took place and ignores the interpretation of the events from either an interpersonal or a legal perspective. At the interpersonal level, Nephew is going to expect Uncle to pay him if he refrains from smoking and drinking until he turns 21 . If

\footnotetext{
2 A survey of six law and AI projects can be found in (Cook, ct. al., 1981).
} 
Uncle does not pay him then Nephew is going to be mad at his Uncle and will probably not trust him again in the future. At the legal level Uncle's promise constitutes an offer and Nephew's agreement constitutes an acceptance. Together they form a contract. ${ }^{4}$ If Uncle does not pay Nephew then the contract has been breached and Nephew can take certain legal action against Uncle to get the money. While it is important to represent the situation at all three levels: physical, interpersonal, and legal, in STARE we have focussed upon representing the legal level.

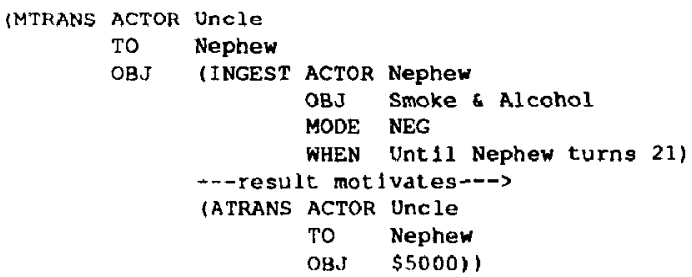

Having decided that $C D$ is not sufficient to represent situations at the legal level, we tried to represent situations using social acts (Schank \& Carbonell, 1979). Social acts were developed to address the inadequacies of $C D$ in representing the social implications of physical acts. Consider the representation for a sentencing a criminal. In CD this would involve an MTRANS from the judge to the criminal that the police are going to PTRANS (physically transfer) the criminal to jail for a certain amount of time. We can make the normal inferences for MTRANS (the criminal now knows the content of the sentence) but this is not enough. There are a myriad of inferences associated with a judge delivering a sentence that the $C D$ level overlooks. One of the inferences is that the criminal may appeal the sentence.

Sentencing a criminal is an example of the social act AUTH which can only be performed by an authority, in this example, the judge. This is actually a circular definition because an authority is one who can AUTH. This circularity will be addressed in our discussion of legal relations (\$2.2). The object of an AUTH is a DECREE which is a statement about the state of the world which affects the recipient of the AUTH. An AUTH also carries with it a DEGREE which is a relative indication of the strength of the AUTH. The AUTH for the judge passing sentence looks like:

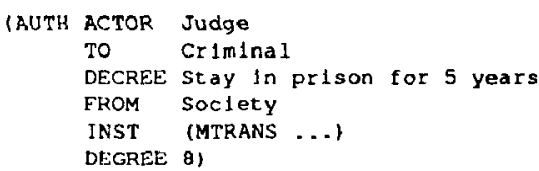

Associated with each social act are two sets of inferences. The first set, called antecedent inferences, describe states that must or may be true before the act took place. In our example, one such inference is that the jury found the criminal guilty. The second set, called consequent inferences, describe states that may result from the act. In our example we know that an appeal may be filed. Many social acts are useful in representing legal disputes and their resolution (see Schank \& Carbonell, 1979 p. 336), but they are not able to represent the actions and inferences which lead to the dispute. Uncle's promise to his Nephew is not an AUTH or an ORDER, it signals that Uncle is willing to enter into a contract; it is an OFFER.

3 Hammer v. Sidway: Cour of Appeals of New York, 1891. 124 N.Y. 538,27 N.E. 256

4 The Statute of Frauds requires that contracts whose performance is over a year in the future must be in writing. This is currently not part of our representation.
We are proposing four basic legal acts as an extension to social acts, which enable us to represent situations involving the formation of contracts by offer and acceptance. Legal acts are not primitive in the same way that $\mathrm{CD}$ acts are primitive because each legal act will have some associated physical manifestation which was instrumental to the act; however, most of the time this instrument does not affect the legal implications of the act. For example, an offer to sell some property may be MTRANSed in a variety of ways (a newspaper advertisement, telephone call). The details of how the offer was communicated, while providing information about who received the offer, have no bearing on the fact that as a result of the offer the recipients have certain legal powers with respect to the offeror. Below we examine in detail the representation and inferences for the basic legal acts OFFER and ACCEPT, 5

\subsubsection{OFFER}

What is an offer? In simplest terms, an offer is a promise from one person (the offeror) to another person (the offeree), that the offeror will perform some action (presumably benefiting the offeree), if the offeree will perform (or promise to perform) some action (benefiting the offeror). This is the representation we showed earlier for promise. That promise appears as the INST (instrument) in the representation of Uncle's promise as a legal offer:

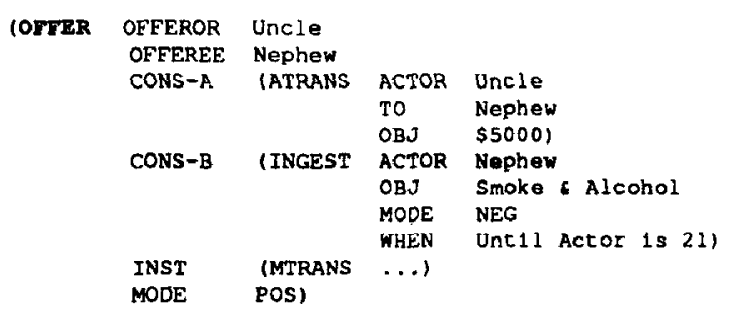

The OFFER act describes the OFFEROR, the OFFEREE, what the offeror has promised to do (CONS-A), what the offeree is supposed to do (CONS-B), how the offer was made (INST), and the status of the offer (MODE). The values and meanings for MODE are:

$\begin{array}{ll}\text { POS } & \text { The offer was extended } \\ \text { NEG } & \text { The offer was not extended } \\ \text { ACCEPTED } & \text { The offer was accepted by an ACCEPT } \\ \text { REJECTED } & \text { The offer was tumed down by a REJECT } \\ \text { REVOKED } & \text { The offeror revoked the offer by a REVOKE }\end{array}$

By itself, the legal act OFFER appears to be merely a new way of packaging old information. What do we gain by this representation? There are two advantages. First, as was pointed out earlier, we want to be able to think about offers without having to consider all the details of when and where the offer was made. The legal act OFFER allows us to ignore this level of representation if we want to. Second, there are the legal implications associated with OFFER which would be inappropriate to attach to MTRANS. The question we must ask is: what exactly are these inferences?

As with social acts, there are two classes of inferences associated with each legal act: antecedent inferences and consequent inferences. Each of these classes contains two types of inferences: required inferences and expectational inferences. Required inferences describe a state of the world which must be true either prior to or following the act. Expectational inferences describe likely states prior to or following the act.

\footnotetext{
5 For a complete description of all four legal acts see (Goldman, 1986).
} 


\section{Antecedent_Inferences}

(1) The offeror must have the right to perform CONS-A with respect to the offeree.

(2) The offeree must have the right to perform CONS-B with respect to the offeror.

Let's examine these inferences using Sober v. Purizan. Starting with the antecedent inferences, (1) states that Uncle must have the right to give Nephew $\$ 5000$. Since there is no law against giving money to another person (and assuming that Uncle has $\$ 5000$ to give) then this poses no problems. This is different from merely having the ability to perform the transfer. Having the ability to perform the act of giving the Nephew $\$ 5000$ is an expectation associated with the common sense concept of offer. (2) states that Nephew must have the right to abstain from smoking and drinking until he turns 21 . If Nephew is under no legal obligation to smoke and drink from the time of the offer until he turns 21 then (2) is satisfied.

\section{Conscauent Inferences}

(1) Offeree has the power to impose a dury on the offeror to perform CONS-A by ACCEPTing the offer.

(2) The offeree has the power to impose a duty on himself to perform CONS-B by ACCEPTing the offer.

(3) The of feror has the right to REVOKE the offer before it is ACCEPTed.

(4) The offeree has the privilege to ACCEPT or REJECT the offer.

Because all the required antecedent inferences were satisfied, we can conclude that Uncle's promise constitutes a legal offer and proceed with the consequent inferences. (1) states that Nephew can legally obligate Uncle to give him $\$ 5000$ when he turns 21 by ACCEPTing the offer. (2) states that Nephew can also legally obligate himself to abstain from smoking and drinking until his $21 \mathrm{st}$ birthday by ACCEPTing the offer. (3) states that Uncle can REVOKE the offer before Nephew ACCEPTs the offer. Finally, (4) states that Nephew can ACCEPT the offer.

\subsubsection{ACCEPT}

Once an offer has been made, one of the actions the offeree can take is to ACCEPT the offer. The acceptance can take one of two forms. Either the offeree can perform the action specified in the offer or the offeree can promise to perform the action. This is the case for Nephew's ACCEPTance:

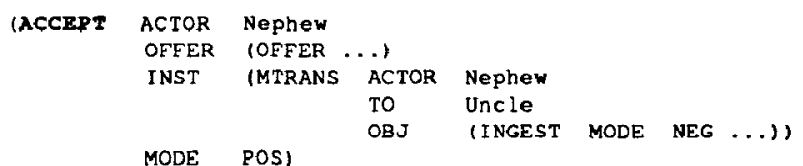

The ACCEPT act specifies the person accepting the offer (ACTOR), the offer that is being accepted (OFFER), how the acceptance was communicated (INST), and whether the acceptance has been made or is intended (MODE).

\section{Antecedent Inferences}

(1) A legal offer was extended to the person trying to ACCEPT. This can also be stated in terms of the legal relations that must exist between the offeror and the offeree.

(2) If the acceptance is made by performing the action, the action performed must be precisely the action that was stated in the offer.

(3) If the acceptance is made by a promise then the promised action must be precisely the action that was stated in the offer.
Inference rule (1) expresses that an acceptance without a preceding offer is meaningless. We can detect the preceding offer by searching for an appropriate event or by looking at the legal relationships between the characters. By accepting the offer, Nephew is trying to exercise his power to create a duty for himself and his Uncle. Rules (2) and (3) state that the acceptance must correspond to the terms of the offer. If Nephew promised only to stop smoking then by (3) we would conclude that the acceptance was not legal.

\section{Consequent Inferences}

(1) The offeree has INVOKEd his power and imposed a duty on the offeror to perform CONS-A.

(2) The offeree has INVOKEd his power and imposed a dury on himself to perform CONS-B.

(3) Offeror and offeree now have a contract.

(4) Offeree likely believes that offeror will follow through if offeree performs the required action.

ACCEPTing the offer changes the legal relationships between Uncle and Nephew. From rules (1) and (2) we know that Nephew has chosen to INVOKE his powers and imposed a duty on his Uncle to pay him $\$ 5000$ when he fulfills his duty of not smoking and drinking until age 21. Rule (3) states that an offer and acceptance constitute a contract.

\subsection{Legal Relationships}

Some examples of the legal relationships in our society are the obligations of public officials to their constituents, freedom of speech, and the right to bear arms. In a contract, we talk about the obligations of the parties involved and their rights if the contract is violated. The problem facing a law student is that there are terms (i.e., right and privilege), which are often used interchangeably although they refer to different legal concepts. A good representation for legal relationships will account for this ease of substitution of terms while clarifying their underlying meanings. We are not the first to attempt this endeavor. (Hohfeld, 1913, 1917) cites many examples of the misuse of terms in his attempt to establish a formal set of legal relations with specific meanings. One example involves the confusion of the terms right and privilege in an excerpt from (Gray, 1909):

The eating of shrimp salad is an interest of mine, and, if I can pay for it, the law will protect that interest, and it is therefore a right of mine to eat shrimp salad which I have paid for, although I know that shrimp salad always gives me the colic.

Hohfeld's analysis of this sentence identifies two relations: the privilege of Gray to eat the salad and the right of Gray to eat the salad. To clarify the difference, Hohfeld associates with each term a correlative term. The correlative for privilege is no-right (a lack of a right), and the correlative for right is duty. Gray's right to eat the salad can be expressed as the duty of another person not to interfere with his eating the salad. Gray's privilege to eat the salad means that another person does not have a right that he should not eat the salad, or to put it another way, Gray does not have a duty to not eat the salad. The previous sentence identifies an opposite term for privilege, namely, duty. The following table shows the relationships of the legal relations defined in (Hohfeld, 1913, 1917):

\begin{tabular}{c} 
Legal Relation \\
\hline Right \\
Privilege \\
Power \\
Immunity
\end{tabular}

$$
\begin{aligned}
& \text { Opnosite } \\
& \text { No-Right } \\
& \text { Duty } \\
& \text { Disability } \\
& \text { Liability }
\end{aligned}
$$


Suppose that Bill offers to sell John his bicycle for $\$ 200$. This is an instance of the legal act OFFER and we infer that John now has the POWER to create a DUTY for Bill to give John the bicycle after John pays him $\$ 200$. By accepting the offer, John is AUTHing a DECREE which states that Bill has a legal obligation (DUTY) to give John the bicycle when John pays him. In order to enforce the AUTH John may have to take Bill to court (PETITION). Legal relations and social acts are highly interdependent. John's POWER to AUTH a DUTY for Bill is:

$$
\begin{aligned}
& \text { IROFER ACTOR JOHA } \\
& \text { ACT IAUTH ACTOR JOhn } \\
& \text { OBJ (LR-DUTY ACTOR BII) } \\
& \text { ACT (ATRANS ...)) } \\
& \text { WRT Bi1 } \\
& \text { WRT John) } \\
& \text { ORIGIN BIll's offer) }
\end{aligned}
$$

As with RIGHTs and PRIVILEGEs, there are certain inferences we can make from POWER. Using our example, the corollary to John's POWER with respect to Bill is a LIABILITY for Bill to incur that DUTY with respect to John. We can also infer that Bill has a DISABILITY (no-power) to pass the LIABILITY to someone else.

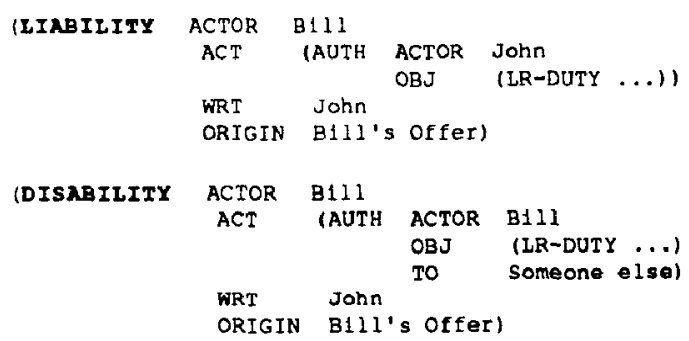

The final legal relation we must consider is IMMUNITY. Intuitively, IMMUNITY is the freedom from someone else's control. If Bill had not extended the offer to John, then Bill would have IMMUNITY against John trying to impose any obligations upon Bill with respect to selling the car.

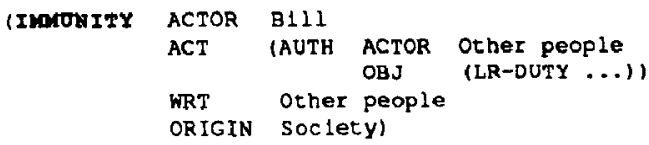

This diagram states that Bill has IMMUNITY with respect to

\begin{tabular}{|c|c|c|c|c|}
\hline \multirow[t]{2}{*}{ (DISABIIITY } & $\begin{array}{l}\text { ACTOR } \\
\text { ACT }\end{array}$ & $\begin{array}{l}\text { Other } \\
\text { (AUTH }\end{array}$ & $\begin{array}{c}\text { people } \\
\text { ACTOR } \\
\text { OBJ }\end{array}$ & \multirow[t]{2}{*}{$\begin{array}{l}\text { Other people } \\
\text { (LR-DUTY ....) }\end{array}$} \\
\hline & $\begin{array}{l}\text { WRT } \\
\text { ORIGIN }\end{array}$ & $\begin{array}{l}\text { Blll } \\
\text { Socie }\end{array}$ & & \\
\hline \multirow[t]{3}{*}{ (LIABILITY } & $\begin{array}{l}\text { ACTOR } \\
\text { ACT }\end{array}$ & $\begin{array}{l}\text { B111 } \\
\text { [AUTH }\end{array}$ & $\begin{array}{l}\text { ACTOR } \\
\text { OBJ }\end{array}$ & $\begin{array}{l}\text { Other people } \\
(\text { LR-DUTY } \ldots \text { ) }\end{array}$ \\
\hline & $\begin{array}{l}\text { WRT } \\
\text { ORIGIN } \\
\text { MODE }\end{array}$ & $\begin{array}{l}\text { Other } \\
\text { Soclet } \\
\text { NEG) }\end{array}$ & $\begin{array}{l}\text { people } \\
y\end{array}$ & \\
\hline & MODE & $\mathrm{NEG}$ & & \\
\hline
\end{tabular}
other people trying to impose obligations upon him. This relation is part of the society we live in. Mary cannot go around creating obligations for Bill unless she has the POWER to do so. This is called DISABILITY and is the corollary to IMMUNITY. We can also infer from IMMUNITY that there is no outstanding LIABILITY for Bill.

\section{Process Model For Understanding Legal Situations}

How do we know when a promise is really a legal offer? How do we recognize legal relationships in everyday situations? The previous two sections describe how to represent world and legal knowledge using CD, goals, plans, states, RTs, I-links, legal $A C T s$, and legal relations. In this section we explore how these knowledge structures interact to enable recognition of legal ACTs and relations from everyday events.

STARE's process model is explanation-based as in the PAM (Wilensky, 1983) and BORIS (Dyer, 1983) programs. In these programs, a conceptual representation for a situation is constructed and augmented by explanations which are generated to handle understanding failures. Understanding consists of applying successively higher level knowledge structures to the input events until a structure is found which can account for the events.

Using a bottom-up approach to recognize legal acts and relations enables us to incorporate this process into a general purpose understanding model. We claim that law students and lay people employ the same understanding processes while reading a case; the difference lies in the knowledge available to those processes.

\subsection{How The Understanding Process Works}

STARE understands cases by searching memory to find knowledge structures which can explain the events in the case. Events can be understood at three levels: act, goal/plan, and legal. STARE's top level algorithm is:

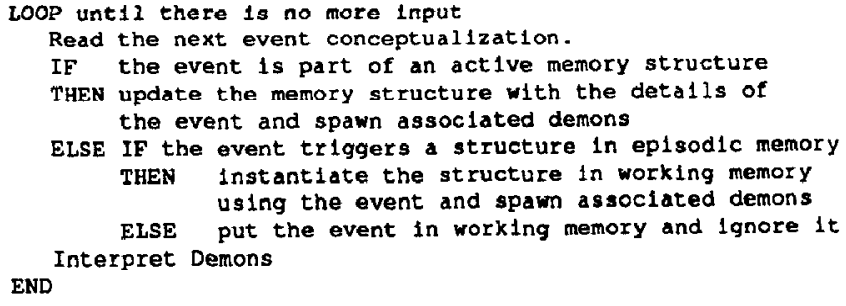

The algorithm is implemented using the DYPAR (Dyer, 1983) demon-based conceptual analyzer. At this point in our research, we have concentrated on developing a representation which enables us to manipulate legal concepts. As a result of this, we have chosen to bypass the issues involved in parsing the English descriptions of cases and instead, analyze conceptualizations which correspond to the English. This raises a serious problem, namely, what is an appropriate intermediate representation? At one extreme, we could start with a full representation of the English using goals, plans, and legal acts but this would defeat our purpose. At the other extreme we have the original English. Our short term solution has been to represent the events in the case using CD ACTs and pass these conceptualizations to our analyzer.

While there are drawbacks to this solution (we lose information conveyed directly by words which aids in handling ambiguity). it has the advantage that the hand-coded representation for cases is easy to produce and has allowed us to focus upon the issues of representation and memory organization. Now we turn our attention to how the input conceptualizations are actually analyzed. Consider the following situation:

\section{Restaurateur $y$. Manager}

Wilma promises Betty that if Wilma acquires a Brontoburger franchise, she will hire Betty as assistant manager. Betty agrees to work for Wilma according to these terms. 
The initial content of the first sentence in this example is shown below. The figure describes the physical event that transpired but lacks a representation of the goals and plans of the characters or the legal implications of the event.

$$
\begin{array}{lll}
\text { (MIRANS ACTOR } & \text { W1lma } \\
\text { TO } & \text { Betty } \\
\text { OBJ } & \text { Betty agree to work for w1lma? } \\
& --7 \text { result motivates --> } \\
& \text { Wilma hire Betty if she gets a franchise) }
\end{array}
$$

As STARE processes input conceptualizations, it constructs a conceptual representation in episodic memory. Associated with initial conceptualizations are demons (delayed procedures) which

\begin{tabular}{|c|c|c|}
\hline & & (IIND-MOP 8 \\
\hline & $=$ & 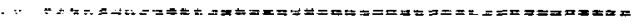 \\
\hline FEST: & iF & $\begin{array}{l}\text { there is an act } 1 \text { ve MOP in work } 1 \text { ng Memory which } \\
\text { matches the current Concept }\end{array}$ \\
\hline ACT: & THEN & $\begin{array}{l}\text { update the active mop using Information from } \\
\text { the current Concept } \\
\text { there is a MOP in Eplsodic Memory which } \\
\text { matches the current Concept }\end{array}$ \\
\hline & $\begin{array}{l}\text { THEN } \\
\text { ELSE }\end{array}$ & $\begin{array}{l}\text { Instant fate the Mop using the current Conc } \\
\text { leave the concept in working Memory }\end{array}$ \\
\hline
\end{tabular}
search memory to find and instantiate higher level knowledge structures which can explain the input. Demons are also used to handle expectations and inferences attached to the instantiated knowledge structures. An example of a search demon is:

FIND-MOP searches the memory structures in working and episodic memory until it finds one whose pattern matches the input conceptualization. If no memory structure is found, the conceptualization remains in working memory unchanged. If a memory structure is found, it is either augmented or instantiated using the bindings from the match. In this example, FINDMOP locates M-OFFER and builds the following conceptualization:

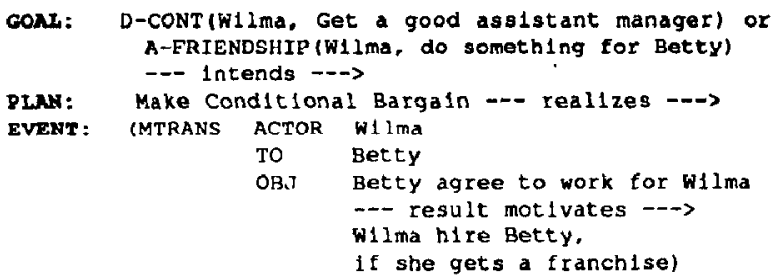

The knowledge contained in M-OFFER allows STARE to infer that Wilma has a goal of either getting a good assistant manager or improving her relationship with Betty and that Wilma has chosen to pursue her goal using the CONDITIONALBARGAIN plan. These inferences are part of the declarative definition of M-OFFER. Also attached to M-OFFER are expectation demons which make predictions about the results of the event. Some of the expectations arising from this example are:

- Betty believes that Wilma will hire her if she gets a franchise.

- Betty believes that accepting Wilma's offer will obligate Wilma to hire Betty if she gets a franchise.

- Betty will either accept or reject Wilma's offer.

If these expectations are violated then failure demons will be spawned to find an explanation for the failure. For example, suppose that after Wilma's offer, the story continued:

Betty didn't believe that Wilma would hire her.
Although not currently implemented, STARE could find an explanation for this expectation failure using the demon:

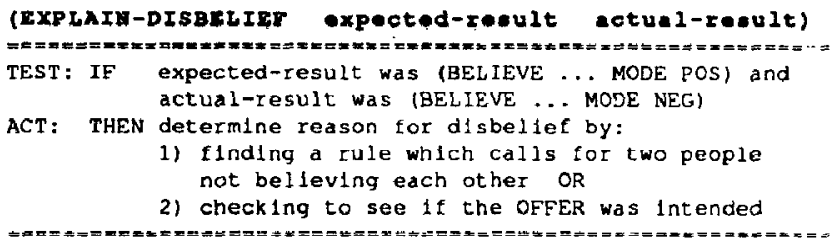

EXPLAIN-DISBELIEF tries to find a reason for Betty not believing Wilma's offer. One way to account for Betty's disbelief is to find a rule which concludes that one person should not believe another person. Two such rules are:

ENEMIES: If $\mathrm{A}$ and $\mathrm{B}$ are enemies and $\mathrm{A}$ promises to do something for $B$, then $B$ will not believe $A$.

CRY-WOLF: If $A$ has repeatedly made promises to $B$ and not kept them, then $B$ will not believe $A$.

Another way to explain Betty's disbelief is to examine how the offer was made to determine whether Wilma really intended to make the offer. For example, if Betty knows that Wilma believes that it is impossible for her to get a franchise then Betty will probably not believe Wilma's offer. The representation of belief and disbelief are an important area for future study.

\subsection{Recognizing Legal Acts and Relations}

In the previous section we showed how STARE uses demonbased parsing to apply the M-OFFER knowledge structure to the first conceptualization of Restaurateur v. Manager. The problem we now face is how to get from M-OFFER to M-LEGALOFFER, the memory structure corresponding to the legal act OFFER. It is not sufficient to look at the structure of the event, the events for M-OFFER and M-LEGAL-OFFER are structurally identical: A promises $B$ that if $B$ does $X$ then $A$ will do $Y$. Instead, STARE checks the preconditions for M-LEGALOFFER against the current situation and, if they are satisfied, instantiates M-LEGAL-OFFER. In this way, STARE only checks for legal offers when a common sense offer has been detected.

Another example of the interaction of common sense and legal knowledge occurs after the legal act OFFER has been detected. One of the consequent inferences is that the offeree will make some kind of response. We use common sense rules (i.e., ENEMIES and CRY-WOLF above) to direct the expectations for the response. For example, in Restaurateur v. Manager, if we know that Betty needs a job then we would expect her to accept the offer.

So far our examples have used common sense knowledge to infer legal ACTs. We can also use legal ACTs to make common sense inferences. In the previous example, if the offeree ACCEPTs the offer (despite the fact that the offeree doesn't trust the offeror), then we would infer that there are additional circumstances that we are unaware of or that the offeree believes that he can force the offeror to follow through. These inferences are different from those associated with the common sense concept of acceptance. At the common sense level, the acceptance is not necessarily binding so we may infer that the offeree is trying to trick the offeror.

\footnotetext{
7 English is used here for simplicity.

8 MOP stands for Memory Organization Packet (Schank, 1982).
} 


\subsubsection{Recognition From Legal Inferences}

As we saw in the previous section, there are many ways of expressing the same legal relation. For example, the RIGHT to vote can also be represented as a DUTY for other people not to interfere with the act of voting. It would be extremely inefficient and cumbersome to make all possible inferences whenever we encounter a legal relation or act, yet there is no guarantee that the relations in a situation will match the ones we are searching for.

For example, consider the situation in Restaurateur v. Manager after the offer has been made. When we see Betty's acceptance, we try to determine whether her acceptance is legal. This means that we must satisfy the required antecedent inferences for ACCEPT. The first precondition is that there was an OFFER. STARE checks this precondition by looking for the legal relations which typically result from an OFFER. Normally, Wilma's OFFER would have resulted in giving Betty certain legal POWERs. However, suppose that Betty had already accepted a job with Rocky and signed a five-year contract. In this case, Betty does not have the POWER to enter into a contract with Wilma. We detect this using the following nules:

1. IF the POWER does not explicitly exist

THEN check for a corresponding DISABILITY

2. IF the DISABILITY does not explicitly exist

THEN check for a corresponding LIABILITY

3. IF the LIABILITY does not explicitly exist

THEN the POWER may or may not exist (unknown).

If, after applying rule (1) we don't find the POWER, then we start searching for a DISABILITY. Rule (2) fires when we fail to find a DISABILITY and now we look for a LIABILITY. At this point we find Betty's LIABILITY to Rocky and can conclude definitely that Betty does not have the requisite POWERs to ACCEPT the offer.

\subsubsection{Remindings and Recognition}

Another way to recognize a legal action or relation is to use previous cases such as:

\section{Madam y. Madam9}

One madam offers to sell her bordello to another madam for $\$ 50,000$. The second madam agrees to purchase the bordello and writes the first madam a check. After receiving the check, the first madam refuses to vacate the premises. The judge rules that although prostitution is illegal, the fact that the property is used as a bordello is incidental and not relevant to the sale.

The important principle in this case is that one can contract to sell something even if they know it might be used for an illegal act. STARE doesn't know this principle, however, it merely knows that a bordello is property used for illegal purposes and that there was a contract in Madam v. Madam. We now ask STARE to analyze a new situation:

\section{Bootlegger $y$. Bootlegger}

Jessie offers to sell Hogg his still for \$1000. Hogg agrees and gives Jessie $\$ 1000$ cash.

STARE knows that stills are objects used for illegal purposes. When STARE looks for the required legal relations for OFFER and ACCEPT, it searches for similar cases in its episodic memory. In this example, STARE finds Madam v. Madam because both involve the sale of an object that can be used for illegal purposes. STARE uses the decision in Madam v. Madam to conclude that there is a contract in Bootlegger v. Bootlegger.

9 Carroll v. Beardon: Sup. Ct. of Minn., 142 Mont. 40, 381 P.2d 295 (1963).

\section{Episodic Memory Structures and Organization}

Law students learning about contract law must remember the cases and principles they read so that when a new case arises, they can recall previous cases to guide their interpretation. STARE stores the cases and principles it knows in episodic memory (Tulving, 1972).

\subsection{Memory Structures}

STARE organizes knowledge structures and episodes using scripts (Schank \& Abelson, 1977) and Memory Organization Packets (MOPs) (Schank, 1982; Dyer, 1983; Kolodner, 1984). Each MOP contains goals, plans, and events which are connected by I-links (Dyer, 1983). The components of a MOP may be shared with other MOPs allowing episodes to be recalled in different contexts as we shall see later. In STARE, scripts are partially instantiated MOPs but there is no sharing of information between scripts. Each MOP has associated antecedent and consequent inferences which determine when it can be instantiated and the effects of the instantiation. STARE's representation of an everyday bilateral (each person is expected to perform some action) offer appears below:

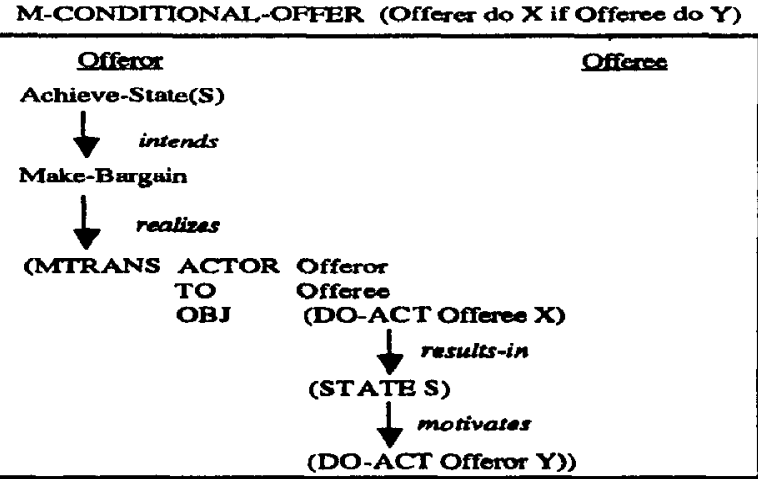

Roles:

Preconditions:

Inferences:

Offeror, Offeree, ACT X, ACT Y, STATE S Offeror and Offeree are HUMAN

Offeror has D-AGENCY goal for Offeree to do ACT X

Offeror believes that (DO-ACT Offeror Y) will achieve some goal for Offeree

M-CONDITIONAL-OFFER describes a situation between two people, the offeror and the offeree, where the offeror wants to get the offeree to perform some task. To achieve this DAGENCY goal, the offeror has chosen to make a bargain with the offeree by performing a task which the offeror believes will achieve a goal for the offeree. This plan is realized by the offeror MTRANSing to the offeree the terms of the bargain. It is interesting to note that there are very few inferences attached to M-CONDITIONAL-OFFER. This is because it is a very general MOP which could apply to thousands of different situations. These general MOPs contain information which is common to all the more specific MOPs they organize. For example, one specification of M-CONDITIONAL-OFFER involves the sale of merchandise. In this case, ACT $X$ is the ATRANS of the merchandise and ACT $Y$ is the ATRANS of money. Attached to this MOP are more specific inferences:

- Offeror must have possession of the object for sale or be acting as an agent for the owner.

- Offeree must be able to pay using some form of currency.

This MOP also inherits all the inferences attached to $M$ CONDITIONAL-OFFER. In this way, inferences are associated with the most general MOP possible. 


\subsection{Indexing Cases In Memory}

STARE's memory is organized hierarchically. At the top are the general MOPs such as M-OFFER and M-CONDITIONALOFFER. Lower in the hierarchy are more specific MOPs such as M-LEGAL-OFFER and M-SALE-OFFER. At the lowest level are scripts (very specific MOPs) and episodes. This organization has been used in CYRUS (Kolodner, 1984) and OCCAM (Pazzani, 1986) and is based upon Schank's dynamic memory (Schank, 1982), which indexes episodes according to surface features and expectation failures.

At the top of the following diagram is a general MOP, MOFFER which describes several types of offers. Two types of offers are unilateral offers and bilateral offers. Unilateral offers involve some action to be performed by the offeror and cannot constitute a legal offer because there is no compensation for the offeror. Bilateral offers require actions from both the offeror and offeree. Unilateral offers are represented by M-SIMPLEOFFER. Bilateral offers are represented by M-COND-OFFER. Indexed under M-COND-OFFER are legal offers and non-legal offers. Legal offers are those which satisfy the preconditions for the legal ACT OFFER and are represented by M-LEGALOFFER. Non-legal offers fail to meet the preconditions and are indexed by those failed preconditions. In the above diagram, the case Merchant v. Copper has been indexed under Fred's conflicting duty to watch Barney's store.

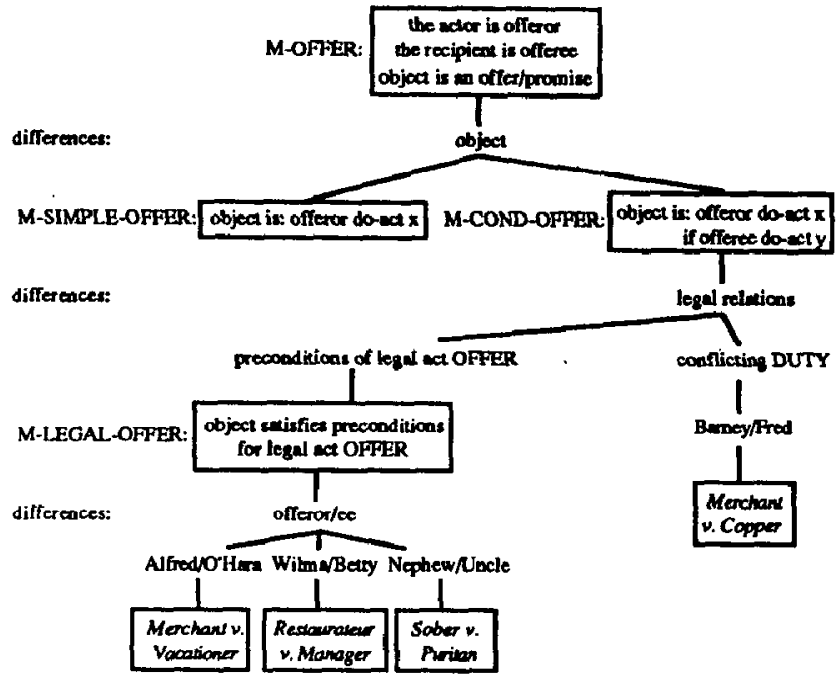

M-LEGAL-OFFER indexes cases where legal offer was extended using their different features. In the diagram the cases are indexed by the offeror and offeree. Other possible indices are role themes of the characters and the content of the offer itself. In fact, all of the cases could be indexed using these features as well. How can we decide which features to use to index a particular case? STARE answers this question by indexing cases using both surface features and conceptual indices and applying heuristics which guide the selection of indices during retrieval. Three heuristics for selecting an appropriate index are:

(1) Prefer conceptual indices specifically, failed preconditions, over surface features.

(2) Choose surface features which are relevant to the particular episode.

(3) If the number of episodes indexed by a particular feature exceeds $\mathbf{N}$

Then reindex those episodes and mark the feature as a bad index.
Thus Merchant v. Copper is indexed by the conflict between Fred's duty to watch Barney's store and his offer to watch the store. The next time STARE sees a situation involving a conflicting duty, it will be able to recall Merchant v. Copper using (1). This would not be possible if the latter were indexed by surface features alone. (2) handles a problem that OCCAM tries to address. For OCCAM, feature relevance is determined by finding an explanation for the episode and checking to see which features are used in the explanation. STARE determines feature relevance by marking features which contribute to the failure of a precondition. Using this criterion, STARE indexes Merchant $v$. Copper by the role theme RT-POLICE-OFFICER because that is source of the conflicting duty which caused the precondition of M-LEGAL-OFFER to fail. Similarly, STARE indexes Merchant $v$. Vacationer using RT-POLICE-OFFICER because O'Hara's occupation is important to the general interpretation of the episode, that is, a police officer would be a good watchman.

As STARE processes more and more cases, it is likely that many cases will be indexed by the same feature. This means that instead of finding a single case to help decide a new case, STARE will encounter a dozen cases. (3) seeks to avoid this problem. We are not making any theoretical claims about the value of $\mathrm{N}$ but our experience and intuition indicate that it should be less than 7. Another way to deal with multiple episodes indexed by the same feature is to construct a new MOP containing the shared features of the episodes and reindexing by their differences.

As law students read new cases they begin to classify the cases according to the legal issues involved. Legal issues correspond to the failure of a precondition for a legal act. For example, suppose that the student has read the cases in the above diagram and now reads Witness $v$. Citizen. The student will construct a new category which corresponds to situations where a person offers to perform some action that they are already supposed to perform. When STARE reads Witness v. Citizen it identifies the failed precondition and using the failure as an index finds Merchant v. Copper. STARE then builds a new MOP, MCOND-OFFER.1, which indexes both cases as shown below: 10

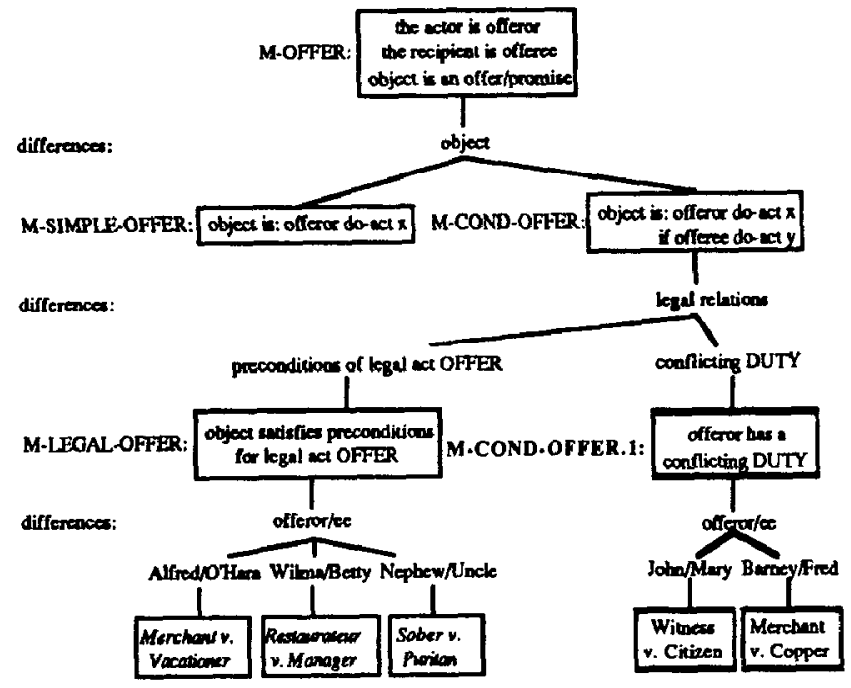

\section{Research in Law and AI}

In $\$ 1.4$ we mentioned some of the other research efforts investigating the applications of artificial intelligence to the law. In this section we shall examine four of these projects.

10 A complete trace of this process can be found in (Goldman, 1986). 


\section{McCarty: The TAXMAN Project}

The TAXMAN project (McCarty \& Sridharan, 1981) is concerned with applying artificial intelligence techniques to legal reasoning and legal argumentation in corporate tax law. The initial program, TAXMAN-I, consists of a representation of the United States Internal Revenue Code that enables it to produce an analysis of the tax consequences of a given corporate transaction. In evaluating the program, McCarty points out that the model is inadequate because it fails to capture the opentexture nature of most legal predicates and does not provide for the creation of new concepts and modification of existing concepts.

In law, the term open-texture refers to a concept which does not have a definite definition but is subject to interpretation based upon the particular situation and how that concept was interpreted in previous cases. A favorite example is:

\section{NO VEHICLES ARE PERMITTED IN THE PARK}

The open-textured term in this case is vehicle. What constitutes a vehicle according to this statute? Are bicycles permitted? Motor scooters? Children's riding toys? What if a person walks a bicycle through the park? By looking at the circumstances surrounding the adoption of this statute we find that there had been numerous complaints about noise in the park. With this information we can interpret vehicles to mean noise producing vehicles.

In order to handle open-textured concepts, McCarty proposed a prototype-plus-deformation model for representing ambiguous terms. The protorype stores the default meaning for a term. The deformations of the prototype consist of a structured set of exemplars, the structure being supplied by a defined set of mappings which specify how to get from the prototype to an exemplar.

The prototype-plus-deformation model is very similar to the organization of STARE's episodic memory. It has been used to represent the decisions in corporate tax cases. We are anxious to see a description of the processes which manipulate the model and see how they compare to STARE's processes.

\section{C. deBessonet: Representation of Legal Knowledge}

Researchers Cary deBessonet and George Cross have been working to develop a conceptual representation for the statutes of the Louisiana State Civil Code (deBessonet \& Cross, 1985). Their methodology is to represent the statutes and then decide which statutes apply to a particular situation and how to apply them. This approach is seductive because statutes are supposed to be unambiguous codification of legal principles. Unfortunately in practice, statutes are subject to two types of ambiguity: structural and semantic (Allen \& Saxon, 1985).

Structural ambiguity occurs when the phrasing of a statute enables multiple interpretations. Consider a statute containing the following sentence:

$$
\begin{array}{lll}
\text { Tr IS PROHIBITED THAT: } & \text { A) ..., B) .... C) ... } \\
\text { UNL ESS: } & \text { D) } \ldots
\end{array}
$$

The meaning is ambiguous and depends upon whether the UNLESS clause, $D$, applies only to clause $C$ or to all three clauses, A, B, and C.

Semantic ambiguity arises through the use of poorly defined or open-textured terms in the text of the statute. One solution to the problem of semantic ambiguity is to use experiential knowledge (the circumstances surrounding the statute's adoption) to aid in disambiguation. This is the kind of experience that STARE stores in episodic memory. When trying to match the vehicle in question with the terms of the statute, we search episodic memory to determine the types of vehicles to which this statute applied and see if the current vehicle qualifies. This is an oversimplified solution but it shows the importance of remembering and using past experience.

\section{Waterman: Evaluating Civil Claims}

A rule-based model of legal expertise is the basis for the Legal Decisionmaking System (LDS) (Peterson \& Waterman, 1985). LDS is a rule-based expert system which determines fair payments for the parties to personal injury cases. Working with lawyers, Peterson and Waterman have identified general rules that personal injury lawyers use to estimate how much a case will be worth and how much to ask for in court.

Cases are analyzed along the dimensions of LOSS (general damages and special damages), LIABILITY (what is responsible for the loss), RESPONSIBILITY (whose fault is it), CHARACTERISTICS (judge, jury, type of client), and CONTEXT (timing and type of claim). These features are combined to arrive at a final value for the case. The values for each dimension are computed by the application of rules such as:

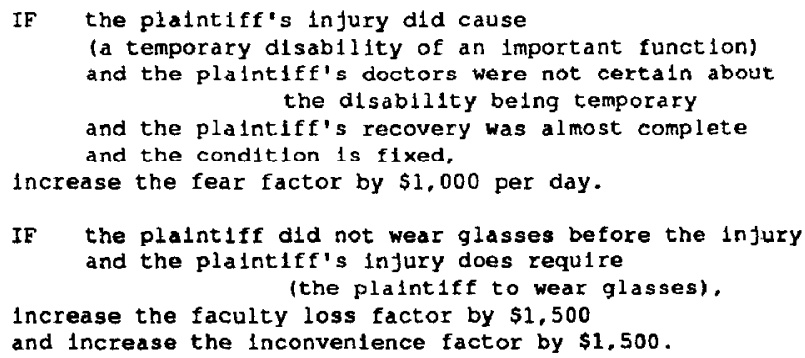

One of the problems with the rule-based approach is that the conceptual model of the domain is implicit in the rules and this means that the program must try all possible rules during its analysis. A better solution would be to store past episodes and use these episodes to decide which rules to apply to a new situation. Citing past cases to justify a decision is more convincing than merely presenting an instantiated rule chain.

\section{A. Gardner: Design of a Legal Analysis Program}

Gardner's research claims to merge expert systems with natural language understanding in a legal reasoning program (Gardner, 1984). The domain is the formation of contracts by offer and acceptance, the same domain STARE currently deals with. The input to the program is a hand-coded representation of a contract law exam question which contains many different issues. The program analyzes this representation and produces as output a graph which is a decision tree with the nodes representing legal questions the program could not resolve.

Gardner 's research serves two purposes. The first is to provide a detailed analysis of the problems and issues that arise in trying to build a legal reasoning system. The second is to address a small set of issues dealing with representing an exam problem and the legal rules involved in offer and acceptance problems.

The major difficulty with this research is that the representation of problems and legal rules is inadequate to model what is actually happening legally. While there is a representation for offer and acceptance acts, there is no representation for legal relations and how they interact with these acts. The theory cannot model situations where there is no contract because one of the parties had a prior duty which conflicted with the offer. Another problem is that there is no memory of past cases. Issue spotting, the task Gardner is tackling, is largely a matter of recalling a past situation and using it to infer the issue in a new situation. Once the issue has been deduced, the case can be used 
to guide the decision in the new case. Finally, there is no attempt to accept natural language input or produce natural language output as was claimed. There is some discussion of speech acts and their relationship to legal acts but there is no model of how one might implement a program which parsed cases into either speech or legal acts.

\section{Conclusions}

In this paper, we have examined the issues involved in constructing a model of first year law students learning contract law. This model is based upon the case method of teaching which presents the students with cases and legal principles together and expects the students to use past cases to understand new situations. We have built a computer program, STARE, which implements this model.

We have developed a representation for legal ACTs and relations which enables us to describe the legal aspects of everyday situations involving offers and acceptances. The representation is comprised of a set of four basic legal ACTs: OFFER, ACCEPT, REVOKE, and REJECT, and a set of eight legal relations: RIGHT, DUTY, PRIVILEGE, NO-RIGHT, POWER, IMMUNITY, DISABILITY, and LIABILITY.

Finally, we have presented a process model which manipulates this representation to understand new situations in terms of previous situations which are stored in an episodic memory. Cases are indexed in memory by legal concepts in addition to surface features. This memory automatically reorganizes itself by creating new structures when two or more episodes share a particular index.

\section{References}

Allen, L.E. and Saxon, C. (1985). "Computer-aided Normalizing and Unpacking: Some Interesting MachineProcessable Transformations of Legal. Rules." In C. Walter (Ed.), Computer Power and Legal Reasoning. West Publishing, St. Paul, MN.

Alvarado, S.J., Dyer, M.G., \& Flowers, M. (1986). "Editorial Understanding in OpEd Through Argument Units." In Proceedings of the National Conference on Artificial Intelligence AAAI-86. Philadelphia, PA.

Cook, S., Hafner, C.D., McCarty, L.T., Meldman, J.A., Peterson, M., Sprowl, J.A., Sridharan, N.S., and Waterman, D.A. (1981). "The applications of artificial intelligence to law: A survey of six current projects." In Proceedings of the AFIPS National Computer Conference. AFIPS Press.

deBessonet, C.G., and Cross, G.R. (1985). "Representation of Some Aspects of Legal Causality." In C. Walter (Ed.), Computer Power and Legal Reasoning. West Publishing, St. Paul, MN.

Dyer, Michael G. (1983). Artificial Intelligence Series: InDepth Understanding: A Computer Model of Integrated Processing For Narrative Comprehension. MIT Press, Cambridge, MA.

Dyer, Michael G., and Flowers, Margot. (1985). "Toward Automating Legal Expertise." In C. Walter (Ed.), Computer Power and Legal Reasoning. West Publishing, St. Paul, MN.

Eisenberg, Melvin A. (1982). Gilbert Law Summaries: Contracts. Harcourt Brace Jovanovich Legal and Professional Publications, Inc.
Gardner, Anne v.d.L. (1984). An Artificial Intelligence Approach to Legal Reasoning. PhD thesis, Stanford University.

Goldman, S.R. (1986). A Process Model of Precedent-based Legal Reasoning and Knowledge Acquisition in Contract Law. Masters Thesis. University of California, Los Angeles.

Goldman, S.R., Dyer, M.G., and Flowers, M. (1985a). "Representing Contractual Situations." In Proceedings of the Second Law and Technology Conference, Houston, TX.

Goldman, S.R., Dyer, M.G., \& Flowers, M. (1985b). "Learning To Understand Contractual Situations." In Proceedings of the 9 th International Joint Conference on Artificial Intelligence. Los Angeles, CA.

Gray. (1909). The Nature and Sources of Law.

Hohfeld, W.N. (1913). "Some Fundamental Legal Conceptions As Applied in Judicial Reasoning." Yale Law Journal. 23:16-59.

Hohfeld, W.N. (1917). "Fundamental Legal Conceptions As Applied in Judicial Reasoning." Yale Law Journal. 710770.

Kolodner, J. (1984). Retrieval and Organizational Strategies in Conceptual Memory: A Computer Model. Hillsdale, NJ. Lawrence Erlbaum Associates.

Kolodner, J., Simpson, R. L. Jr., Sycara, K. (1985). "A Process Model of Cased-Based Reasoning in Problem Solving." In Proceedings of the Ninth International Joint Conference on Artificial Intelligence, (IJCAI-85). Los Angeles, CA.

McCarty, L. T., and Sridharan, N.S. (1981). A Computational Theory of Legal Argument. Technical Report LRP-TR-13, Laboratory for Computer Science Research, Rutgers University.

Meldman, J. A. (1975). A Preliminary Study in ComputerAided Legal Analysis. PhD thesis, Massachusetts Institute of Technology. Technical Report No. MAC-TR-157.

Pazzani, M.J. (1985), "Explanation and Generalization Based Memory." In Proceedings of the Seventh Annual Conference of the Cognitive Science Society. Irvine, CA.

Peterson, Mark A. and Waterman, Donald A. (1985). "Evaluating Civil Claims: An Expert Systems Approach." In C. Walter (Ed.), Computer Power and Legal Reasoning. West Publishing, St. Paul, MN.

Schank, R. C. \& Abelson, R. (1977). Scripts, Plans, Goals, and Understanding. Lawrence Erlbaum.

Schank, Roger. C., and Carbonell, Jaime. G., Jr. (1979). "Re: The Gettysburg Address: Representing social and political acts." In N. Findler (Ed.), Associative Networks. Academic Press.

Schank, R. C. (1982). Dynamic Memory. Cambridge. Cambridge University Press.

Tulving, E. (1972). "Episodic and Semantic Memory." In E. Tulving and W. Donaldson (editors), Organization of Memory. Academic Press, New York.

Wilensky, R. (1983). Planning and Understanding: A Computational Approach to Human Reasoning. AddisonWesley, Reading, MA. 